\title{
Comparison of biomass component equations for four species of northern coniferous tree seedlings
}

\author{
Robert G. Wagner*, Michael T. Ter-Mikaelian \\ Ontario Forest Research Institute, Sault Ste. Marie, Ontario, P6A 2E5, Canada
}

(Received 10 November 1997; accepted 10 November 1998)

\begin{abstract}
We compare equations predicting the biomass components (foliage, branches, stem, roots, total aboveground and total tree) for seedlings of four coniferous tree species: jack pine (Pinus banksiana Lamb.), red pine (Pinus resinosa Ait.), eastern white pine (Pinus strobus L.) and black spruce (Picea mariana (Mill.) B.S.P.) grown under controlled experimental conditions for 3 years. Coefficients of determination $\left(R^{2}\right)$ for the component equations exceeded 0.9 for jack and red pine, and ranged from 0.7 to 0.9 for white pine and black spruce. Basal diameter was the most important variable in all equations. Adding crown width improved the adjusted $R^{2}$ for total, aboveground, branch and foliage biomass equations by $2.5 \%$. Adding tree height improved the adjusted $R^{2}$ for stem biomass equations by $6.2 \%$. Root biomass equations were not improved by including height or crown width. Using statistical comparisons of the full model (i.e. separate equations for each species) with three alternative reduced models that pooled various combinations of species, we determined that none of the biomass component equations could be combined among the four conifer species. (C Inra/Elsevier, Paris.)
\end{abstract}

biomass prediction / jack pine / Pinus banksiana / red pine / Pinus resinosa / white pine / Pinus strobus / black spruce / Picea mariana

Résumé - Comparaison d'équations des composantes de la biomasse pour des jeunes plants de quatre espèces de conifères canadiens. Nous avons développé et comparé des équations de prédiction des composantes de la biomasse (feuillage, branches, tronc, racines, total aérien et total arbre) pour des jeunes plants de quatre espèces de conifères: pin gris (Pinus banksiana Lamb.), pin rouge (Pinus resinosa Ait.), pin blanc (Pinus strobus L.) et épicéa noir (Picea mariana (Mill.) B.S.P) cultivés sous conditions expérimentales controlées pendant trois ans. Les coefficients de détermination $\left(R^{2}\right)$ pour les équations des composantes excèdent 0,9 pour le pin gris et le pin rouge, et varient entre 0,7 et 0,9 pour le pin blanc et l'épicéa noir. Le diamètre basal était la variable la plus importante dans toutes les équations. L'ajout de la largeur de la couronne améliore de $2,5 \%$ le $R^{2}$ ajusté pour les équations du total, de l'aérien, des branches et du foliage. L'ajout de la hauteur de l'arbre améliore le $R^{2}$ ajusté de $6,2 \%$ pour la biomasse du tronc. Les équations de la biomasse racinaire n'étaient pas améliorées par l'ajout de la largeur de la couronne ou la hauteur. En utilisant des comparaisons statistiques du modèle entier (i.e., équations séparées pour chaque espèce) avec trois modèles simplifiés qui regroupent différentes combinaisons d'espèces, nous avons déterminé qu'aucune équations des composantes de la biomasse ne pouvaient être combinées pour décrire plus d'une espèce. (@ Inra/Elsevier, Paris.)

prédiction de la biomasse / pin gris / Pinus banksiana / pin rouge / Pinus resinosa / pin blanc / Pinus strobus / épicéa noir / Picea mariana

\footnotetext{
* Correspondence and reprints: Department of Forest Ecosystem Science, University of Maine, 5755 Nutting Hall, Orono, ME 04469-5755, USA

Bob_Wagner@umenfa.maine.edu
} 


\section{INTRODUCTION}

Forest managers and researchers require biomass equations to predict the growth of young forest stands. Predicting tree biomass is important for a) developing indicators of forest productivity [2], b) quantifying patterns of forest succession [17], c) estimating potential carbon sequestering in forest stands [11], and d) modeling forest growth at both tree and stand levels [9].

Although abundant equations for biomass prediction have been developed for mature trees [15], relatively few studies have focused on young trees. Biomass equations for trees in seedling and sapling stages have been developed a) for forest fuel inventories [1], b) for assessing the potential of young stands as fiber sources [7], c) as an indicator of net primary production [14], and d) for other purposes $[11,13,18,19]$. Few papers report component biomass equations for northern coniferous species: spruce (Picea spp.) [13, 19], red pine [11, 19] and eastern white pine [19].

There have been a number of attempts to compare biomass equations for mature trees across a range of site and stand conditions. For example, Feller [4] compared equations developed from both good and poor sites for Douglas-fir (Pseudotsuga menziesii (Mirb.) Franco) and western red cedar (Thuja plicata Donn). Koerper and Richardson [8] examined equations for largetooth aspen (Populus grandidentata Michx.) growing on different sites. We found no published attempts, however, to compare biomass equations among forest tree species. To properly compare biomass equations among tree species, it is important that each species be grown under identical conditions to avoid confounding with environmental factors. It has been shown that biomass equations can vary significantly for the same tree species when they are grown under different environmental conditions [4, 8].

We develop and compare equations predicting the biomass components (foliage, branches, stem, roots, total aboveground and total tree) for seedlings of four coniferous tree species: jack pine, red pine, eastern white pine and black spruce grown under controlled experimental conditions for 3 years.

\section{MATERIALS AND METHODS}

\subsection{Experimental design}

A site $50 \mathrm{~km}$ north of Sault Ste. Marie, Ontario, Canada in the Great Lakes/St. Lawrence forest type was selected for study. The site, which is flat and has a sandy-textured soil, was clearcut harvested from 1987-1989. In July 1991, the site was prepared for plant- ing with a Donaren disk trencher and shortly thereafter became dominated by herbaceous vegetation. Black spruce, jack pine, eastern white pine and red pine seedlings were planted in a randomized complete block, split-plot design with six treatments and four blocks (replications) on the site.

Planting stock of each species was obtained for the seed zone from local nurseries and planted in mid-May 1992. The stock types were: jack pine - container, multipot 67 with $57 \mathrm{cc}$ volume (height $=10.7 \mathrm{~cm}$, stem diameter $=3.1 \mathrm{~mm}$ ), red pine $-2+0$ medium bareroot (height $=9.2 \mathrm{~cm}$, stem diameter $=4.3 \mathrm{~mm}$ ), white pine $\mathrm{G}+1.5$ medium bareroot (height $=9.5 \mathrm{~cm}$, stem diameter $=4.9 \mathrm{~mm}$ ) and black spruce $-\mathrm{G}+2$ medium bareroot (height $=29.3 \mathrm{~cm}$, stem diameter $=5.2 \mathrm{~mm}$ ). These stock types are typical of those used for these species when planted on similar sites in Ontario.

Six treatments were used to control all herbaceous vegetation in a sequential pattern for the first 3 years (1992-1994) after tree planting, producing various degrees of interspecific competition around the tree seedlings. These differing environments produced a population of trees with a range of sizes from which biomass prediction equations could be developed (table I). Our objective was not to compare equations among treatments, but to use pooled data from all treatments to compare equations developed for different species growing under identical environmental conditions. Additional details about the site and experimental design can be found in Wagner et al. [16].

\subsection{Biomass sampling}

In late October 1994, two trees of each species were randomly selected from each plot; providing a total of 48 sample trees (two trees $\times$ six treatments $\times$ four blocks) of each conifer species for analysis. The total height $(\mathrm{cm})$ (from ground to base of the terminal bud), basal stem diameter (mm) (just above the swell of the root collar) and crown width $(\mathrm{cm})$ (average of two perpendicular dimensions) were measured for each tree.

Each tree was then extracted from the soil using a shovel. The loose sandy soil allowed each root system to be removed nearly intact. Each tree was tagged, placed in a plastic bag and stored in a cooler.

Dissection of each tree included thoroughly washing soil from the roots, separating roots and branches (with needles attached) from the main stem, and placing each of three components into separate paper bags. All bags were dried in an oven at $70^{\circ} \mathrm{C}$ for $72 \mathrm{~h}$. Immediately upon removal from the oven, each bag with contents was weighed $(\mathrm{g})$. The contents of each bag were removed and 
Table I. General statistics for variables used in biomass analysis. See text for definition of variables.

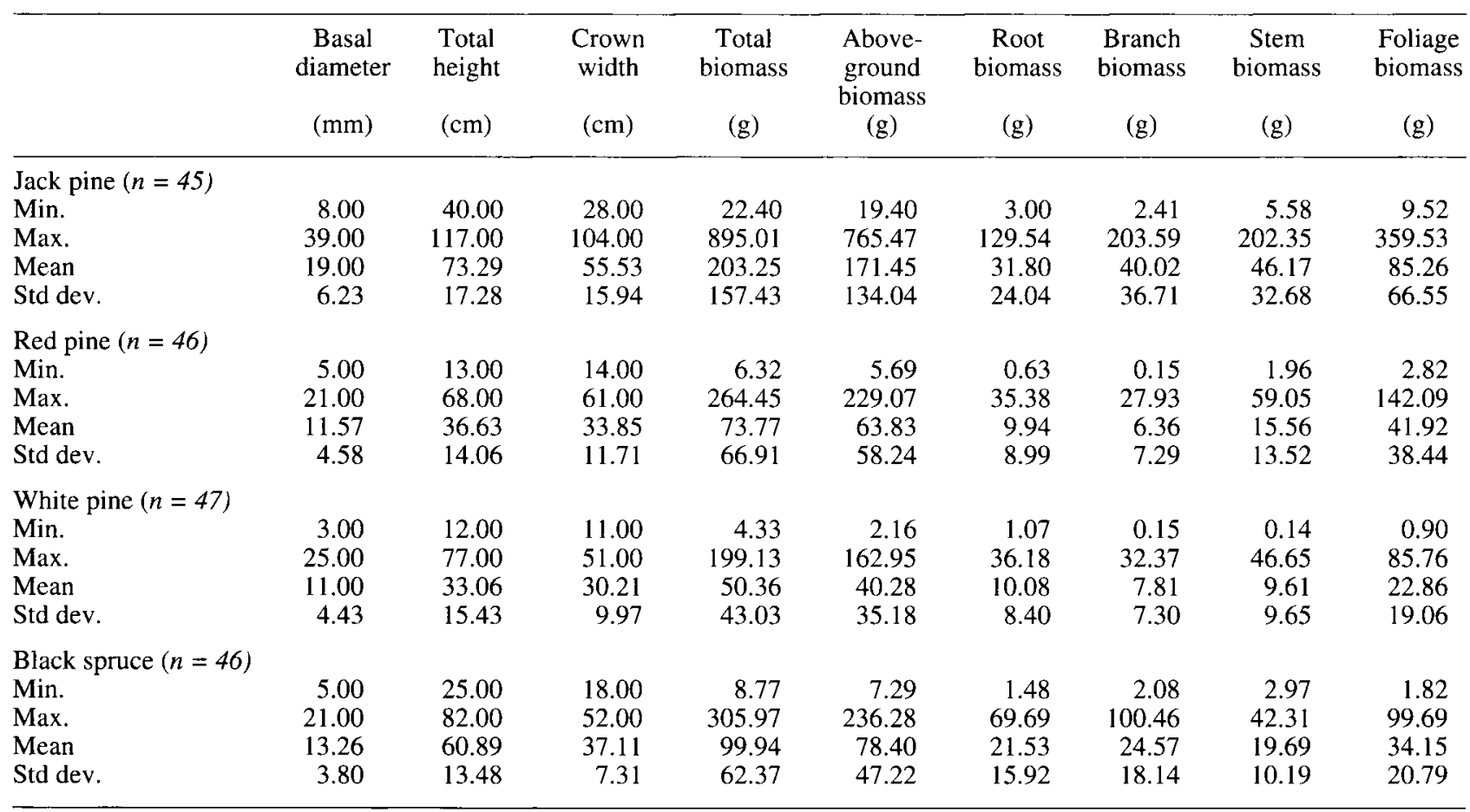

the empty bag weighed. After weighing bags containing needles and branches, all needles were separated from branches by hand and the branches weighed alone. The bag weight was subtracted from the total to calculate the weight of each component.

\subsection{Equation development}

Equations were developed for each tree species and biomass component (roots, stem, branches, foliage), plus combined elements (total, aboveground), using regression analysis. A non-linear model form used most often for tree biomass modeling is

$$
M=b_{0} D^{b_{1}} C^{b_{2}} H^{b_{3}}
$$

where $M$ is a biomass ( $\mathrm{g}$ ) of the component, $D$ is the basal diameter $(\mathrm{mm})$ of the tree stem at the ground level, $C$ is the crown width $(\mathrm{cm}), H$ is total height $(\mathrm{cm})$ and $b_{0}$, $b_{1}, b_{2}$ and $b_{3}$ are parameters [15].

Use of equation (1), however, tends to produce heteroscedastic residuals. Two approaches to dealing with this problem are to use weighted least squares with equation (1) or a linear form using log transformations.

$$
\text { Ln } M=\ln b_{0}+b_{1} \ln D+b_{2} \ln C+b_{3} \ln H
$$

After comparing both approaches, we chose equation (2) because 1) we found no difference in the normality or homogeneity of residuals, 2) Furnival's index of fit [6] was similar, and 3) the advantage of using standard linear regression methods allowed us to quantitatively compare biomass component models among species, our principal objective. In discussing both approaches, Ratkowsky [10] suggests using linear models when both approaches are able to accomplish the modeling objective (i.e., homogenize and normalize residuals).

For ease of interpretation, we report the equations (regression coefficients) in back-transformed units. One limitation with using log models is the need to correct for bias when back-transforming model predictions. Therefore, we added one half of the standard error of estimate squared $\left(1 / 2(\mathrm{SEE})^{2}\right)$ to the intercept of equation (2) prior to taking the exponent to correct for bias [3].

During the analysis, several seedlings were identified (using scatterplots and Studentized residual threshold values $>3.0$ ) as consistent outliers for all biomass components. We investigated potential causes for their departure from other observations and ruled out measurement error as well as other experimental factors. 
Therefore, we removed three jack pine, two red pine, one white pine and two black spruce, reducing the final sample size to $45,46,47$ and 46 for jack pine, red pine, white pine and black spruce, respectively. Seber [12] indicates that outliers with Studentized residual values greater than 3.0 can be removed if $n>20$. Our outliers and sample size met both conditions.

Using equation (2) for each biomass component for each species, equations with all possible combinations of variables $D, C, H$ were examined. We selected those equations where these variables were significant $(P<0.05)$ and produced equations with the highest adjusted $R^{2}$ (referred to as the 'best' equation throughout this paper). We sought consistency among component equations to facilitate equation comparisons among species. To ensure consistency with other published equations for tree biomass [15], we also provide equations that include only basal diameter $(D)$ referred to as the 'base' equation.

\subsection{Species comparisons}

To determine whether the same biomass component equations could be applied to all four tree species, we systematically tested whether the equations were statistically different among species. An a priori approach was used that compared the full model (i.e., separate equations for each species) with three reduced model forms that pooled the species in various combinations based on taxonomical and morphological features. We tested sequentially (for each biomass component) whether the full model accounted for more variation than: a) a reduced model pooling all species, b) a reduced model pooling all pine species plus black spruce, and c) a reduced model pooling red and white pine (bareroot stock) plus jack pine (container stock) plus black spruce. The best equation for each biomass component was used in all comparisons. An insignificant result (i.e., $P>0.05$ ) at any step would terminate any further model comparisons for that component.

Each comparison was evaluated using $F$-tests. $F$-statistics were calculated using the ratio of the difference between the residual sum of squares for the reduced and full models to the residual sum of squares for the full model divided by the appropriate degrees of freedom [12]. The $P$-value was calculated as a percentile of the $F$ distribution with the respective degrees of freedom.

\section{RESULTS}

The final equations are presented in table II. Two equations are presented for each biomass component: a) the best equation derived using variables $D, C$ and $H$, and b) the base equation with basal diameter $(D)$ only. Parameters $b_{0}, b_{1}, b_{2}$ and $b_{3}$ apply to equation (1) and are back transformed. In addition, $b_{0}$ has been corrected for logarithmic bias. The coefficient of determination $\left(R^{2}\right)$ and the standard error of estimate (SEE) are presented for both $\log$ and back-transformed equations.

Basal diameter $(D)$ was the most important variable in all equations. Adding crown width $(C)$ improved equations for total, aboveground, branch and foliage biomass. Including tree height $(H)$ improved only the stem biomass equations. Root biomass equations were not improved by including $C$ or $H$. All variables $(D, C$ and $H)$ in the equations were significant $(P<0.001)$. The only exceptions were including $C$ in equations for jack pine and black spruce, where $P$-values ranged between 0.01 and 0.09 .

Results from the three comparisons determining whether the biomass equations were different among species are presented in table III. We found that accounting for each species (full model) was significantly better $(P<0.0001)$ for all biomass component equations than pooling all species (comparison \#1, table III). The full model also was superior $(P<0.0012)$ to a model pooling the three pine species (comparison \#2). Accounting for differences in the origin of the pine planting stock (comparison \#3), by separating equations based on whether the seedlings came from bareroot stock (red and white pine) or container stock (jack pine), also did not improve $(P<0.0068)$ any of the component equations relative to the full model.

\section{DISCUSSION}

From the results of our three comparisons (table III), we conclude that the biomass component equations presented in table II can not be combined for any of the four conifer species. Despite the fact that all species were grown under identical experimental conditions, different biomass equations were required. Therefore, all relationships appear to be species specific.

We were able to construct equations for all biomass components that accounted for most of the variation. Coefficients of determination $\left(R^{2}\right)$ were highest $(>0.9)$ for jack and red pine, and somewhat lower $(0.7-0.9)$ for white pine and black spruce.

Basal diameter was the best variable among the three examined to predict all biomass components, confirming 
Table II. Biomass equation of the form $M=b_{0} D^{b l} C^{b 2} H^{b 3}$, where $M$ is a biomass (g) component, $D$ is basal diameter (mm), $C$ is the crown width (cm), $H$ is total height $(\mathrm{cm})$, and $b_{0}, b_{1}, b_{2}$, and $b_{3}$ are parameters. Parameter $b_{0}$ is corrected for logarithmic bias.

\begin{tabular}{|c|c|c|c|c|c|c|c|c|}
\hline \multirow[b]{2}{*}{ Component } & \multirow[b]{2}{*}{$b_{0}$} & \multirow[b]{2}{*}{$b_{1}$} & \multirow[b]{2}{*}{$b_{2}$} & \multirow[b]{2}{*}{$b_{3}$} & \multicolumn{2}{|c|}{ Logarithmic } & \multicolumn{2}{|c|}{ Back-transformed } \\
\hline & & & & & $R^{2}$ & SEE & $R^{2}$ & SEE \\
\hline \multicolumn{9}{|c|}{ Jack pine $(n=45)$} \\
\hline \multirow[t]{2}{*}{ Total } & 0.0884 & 1.9719 & 0.4442 & - & 0.986 & 0.099 & 0.978 & 23.32 \\
\hline & 0.1942 & 2.3115 & - & - & 0.981 & 0.111 & 0.976 & 24.38 \\
\hline \multirow[t]{2}{*}{ Above } & 0.0676 & 1.9043 & 0.5179 & - & 0.984 & 0.103 & 0.978 & 19.73 \\
\hline & 0.1694 & 2.3002 & - & - & 0.978 & 0.119 & 0.974 & 21.75 \\
\hline Roots & 0.0255 & 2.3713 & - & - & 0.955 & 0.179 & 0.925 & 6.58 \\
\hline \multirow[t]{2}{*}{ Stem } & 0.0098 & 1.6677 & - & 0.8049 & 0.979 & 0.100 & 0.984 & 4.18 \\
\hline & 0.1658 & 1.8835 & - & - & 0.908 & 0.208 & 0.912 & 9.67 \\
\hline \multirow[t]{2}{*}{ Branches } & 0.0025 & 2.3916 & 0.5992 & - & 0.967 & 0.185 & 0.916 & 10.62 \\
\hline & 0.0072 & 2.8497 & - & - & 0.962 & 0.197 & 0.907 & 11.19 \\
\hline \multirow[t]{2}{*}{ Foliage } & 0.0360 & 2.0433 & 0.3980 & - & 0.972 & 0.141 & 0.945 & 15.59 \\
\hline & 0.0728 & 2.3476 & - & - & 0.968 & 0.147 & 0.947 & 15.30 \\
\hline \multicolumn{9}{|c|}{ Red pine $(n=46)$} \\
\hline \multirow[t]{2}{*}{ Total } & 0.0333 & 1.6673 & 0.9584 & - & 0.983 & 0.137 & 0.983 & 8.70 \\
\hline & 0.1441 & 2.4529 & - & - & 0.969 & 0.181 & 0.969 & 11.71 \\
\hline \multirow[t]{2}{*}{ Above } & 0.0254 & 1.6198 & 1.0271 & - & 0.979 & 0.154 & 0.977 & 8.88 \\
\hline & 0.1219 & 2.4618 & - & - & 0.963 & 0.199 & 0.961 & 11.47 \\
\hline Roots & 0.0224 & 2.3991 & - & - & 0.963 & 0.196 & 0.951 & 1.99 \\
\hline \multirow[t]{2}{*}{ Stem } & 0.0215 & 1.6522 & - & 0.6531 & 0.953 & 0.209 & 0.950 & 3.02 \\
\hline & 0.0566 & 2.2180 & - & - & 0.931 & 0.251 & 0.895 & 4.38 \\
\hline \multirow[t]{2}{*}{ Branches } & 0.0003 & 1.4979 & 1.7110 & - & 0.886 & 0.443 & 0.882 & 2.51 \\
\hline & 0.0037 & 2.9005 & - & - & 0.859 & 0.487 & 0.878 & 2.55 \\
\hline \multirow[t]{2}{*}{ Foliage } & 0.0099 & 1.4786 & 1.2720 & - & 0.969 & 0.191 & 0.964 & 7.29 \\
\hline & 0.0690 & 2.5214 & - & - & 0.947 & 0.246 & 0.951 & 8.54 \\
\hline \multicolumn{9}{|c|}{ White pine $(n=47)$} \\
\hline Total & 0.0395 & 1.406 & 1.0568 & - & 0.954 & 0.204 & 0.935 & 10.98 \\
\hline & 0.2258 & 2.1899 & - & - & 0.904 & 0.293 & 0.835 & 17.49 \\
\hline Above & 0.0175 & 1.3576 & 1.2593 & - & 0.945 & 0.239 & 0.912 & 10.44 \\
\hline & 0.1404 & 2.2918 & - & - & 0.882 & 0.346 & 0.787 & 16.25 \\
\hline Roots & 0.1017 & 1.8708 & - & - & 0.807 & 0.377 & 0.806 & 3.70 \\
\hline Stem & 0.0062 & 1.3297 & - & 1.1435 & 0.853 & 0.426 & 0.935 & 2.45 \\
\hline & 0.0337 & 2.3015 & - & - & 0.743 & 0.558 & 0.745 & 4.87 \\
\hline Branches & 0.0012 & 1.1746 & 1.6778 & - & 0.885 & 0.384 & 0.908 & 2.21 \\
\hline & 0.0203 & 2.4191 & - & - & 0.794 & 0.508 & 0.738 & 3.74 \\
\hline Foliage & 0.0062 & 1.2925 & 1.4500 & - & 0.901 & 0.341 & 0.798 & 8.57 \\
\hline & 0.0681 & 2.3681 & - & - & 0.828 & 0.446 & 0.590 & 12.20 \\
\hline Black spruce & & & & & & & & \\
\hline Total & 0.1764 & 1.7233 & 0.5007 & - & 0.864 & 0.254 & 0.868 & 22.69 \\
\hline & 0.5419 & 1.9902 & - & - & 0.854 & 0.260 & 0.835 & 25.29 \\
\hline Above & 0.151 & 1.6366 & 0.5403 & - & 0.870 & 0.239 & 0.864 & 17.43 \\
\hline & 0.5072 & 1.9246 & - & - & 0.858 & 0.247 & 0.828 & 19.58 \\
\hline Roots & 0.0571 & 2.2575 & - & - & 0.749 & 0.413 & 0.782 & 7.43 \\
\hline Stem & 0.0194 & 1.3156 & - & 0.8422 & 0.924 & 0.173 & 0.906 & 3.12 \\
\hline & 0.1588 & 1.8445 & - & - & 0.878 & 0.217 & 0.864 & 3.75 \\
\hline Branches & 0.027 & 1.5252 & 0.7743 & - & 0.709 & 0.403 & 0.735 & 9.33 \\
\hline & 0.1533 & 1.9379 & - & - & 0.689 & 0.411 & 0.690 & 10.11 \\
\hline Foliage & 0.0373 & 1.7429 & 0.6217 & - & 0.826 & 0.307 & 0.814 & 8.97 \\
\hline & 0.1504 & 2.0743 & - & - & 0.813 & 0.314 & 0.770 & 9.97 \\
\hline
\end{tabular}


Table III. Results ( $F$ - and $P$-values) from a sequential comparison of the full model (i.e., separate equations for each species) with three alternative reduced models for each biomass component. The best equation for each component in table II was used.

\begin{tabular}{|c|c|c|c|c|c|c|}
\hline \multirow[b]{2}{*}{ Biomass component: } & \multicolumn{2}{|c|}{$\begin{array}{l}\# 1 \\
\text { reduced model } \\
\text { pooling all species }\end{array}$} & \multicolumn{2}{|c|}{$\begin{array}{l}\text { Comparison of full model versus } \\
\# 2 \\
\text { reduced model pooling all pine } \\
\text { species plus black spruce }\end{array}$} & \multicolumn{2}{|c|}{$\begin{array}{c}\# 3 \\
\text { reduced model pooling white } \\
\text { and red pine (bareroot stock) } \\
\text { plus jack pine (container stock) } \\
\text { plus black spruce }\end{array}$} \\
\hline & $F(9,172)^{\mathrm{a}}$ & $P$-value & $F(6,172)^{\mathrm{b}}$ & $P$-value & $F(3,172)^{\mathrm{c}}$ & $P$-value \\
\hline Roots & 14.68 & $<0.0001$ & 6.55 & 0.0001 & 11.52 & $<0.0001$ \\
\hline Stem & 7.14 & $<0.0001$ & 9.05 & $<0.0001$ & 16.52 & $<0.0001$ \\
\hline Branches & 35.91 & $<0.0001$ & 15.33 & $<0.0001$ & 26.01 & $<0.0001$ \\
\hline Foliage & 10.24 & $<0.0001$ & 14.58 & $<0.0001$ & 12.60 & $<0.0001$ \\
\hline
\end{tabular}

a For roots, the degrees of freedom are 6 and 176.

${ }^{\mathrm{b}}$ For roots, the degrees of freedom are 4 and 176.

${ }^{\mathrm{c}}$ For roots, the degrees of freedom are 2 and 176.

the work of others $[14,18]$. The addition of crown width and height only slightly improved the equations. Average $R^{2}$ values for the base equations predicting total, aboveground, branch and foliage biomass (16 equations) was 0.891 . Adding crown width to these equations improved the average $R^{2}$ to 0.918 (increasing the adjusted $R^{2}$ by $2.53 \%$ ). The addition of height to the stem biomass equation increased the average $R^{2}$ from 0.865 to $0.927\left(6.22 \%\right.$ increase in average adjusted $\left.R^{2}\right)$.

Despite the common use of the total height as a predictor variable in tree biomass equations, it only significantly improved equations for stem biomass. This result contrasts with those of Hitchcock [7] and Young et al. [19], who found seedling height to be the best predictor of biomass components. Our finding is consistent, however, with Freedman et al. [5] who found that height accounted for a smaller proportion of the variation than did stem diameter for ten species of mature trees (conifers and hardwoods).

Acknowledgements: This publication was supported by VMAP (Vegetation Management Alternatives Program) through the Ontario Ministry of Natural Resources. We thank Drs Gina Mohammed and Tom Noland for advice about methods for biomass collection. Ago Lehela, Wanda Nott and John Winters provided valuable technical assistance with field and laboratory work. Drs Doug Pitt and David Ratkowsky provided helpful advice about the statistical analysis. Dr JeanNoël Candau provided a French translation for the abstract.

\section{REFERENCES}

[1] Agee J.K., Fuel weights of understory-grown conifers in southern Oregon, Can. J. For. Res. 13 (1983) 648-656.

[2] Baskerville G.L., Dry-matter production in immature balsam fir stands, Soc. Am. For., Wash., DC, For. Sci. Monogr. 9 (1965).

[3] Baskerville G.L., Use of logarithmic regression in the estimation of plant biomass, Can. J. For. Res. 2 (1972) 49-53.

[4] Feller M.C., Generalized versus site-specific biomass regression equations for Pseudotsuga menziesii var menziesii and Thuja plicata in Coastal British Columbia, Bioresour. Tech. 39 (1992) 9-16.

[5] Freedman B., Duinker P.N., Barclay H., Morash R., Prager U., Forest biomass and nutrient studies in central Nova Scotia, Can. For. Serv., Maritimes For. Res. Cen., Info. Rep. M-X-134, 1982.

[6] Furnival G.M., An index for comparing equations used in constructing volume tables, For. Sci. 7 (1961) 337-341

[7] Hitchcock H.C. III, Aboveground tree weight equations for hardwood seedlings and saplings, TAPPI 61 (1978) 119-120.

[8] Koerper G.J., Richardson C.J., Biomass and net annual primary production regressions for Populus grandidentata on three sites in northern lower Michigan, Can. J. For. Res. 10 (1980) 92-101.

[9] Korzukhin M.D., Ter-Mikaelian M.T., Wagner R.G., Process versus empirical models: which approach for forest ecosystem management?, Can. J. For. Res. 26 (1996) 879-887.

[10] Ratkowsky D.A., Nonlinear Regression Modeling: A Unified Practical Approach, Marcel Dekker, New York, 1983.

[11] Reed D.D., Mroz G.D., Liechty H.O., Jones E.A., Cattelino P.J., Balster N.J., Zhang Y. Above- and below- 
ground biomass of precompetitive red pine in northern Michigan, Can. J. For. Res. 25 (1995) 1064-1069.

[12] Seber G.A.F., Linear Regression Analysis, John Wiley and Sons, New York, 1977.

[13] Smith W.B., Brand G.J., Allometric biomass equations for 98 species of herbs, shrubs, and small trees, USDA For. Serv., North. Cen. For. Exp. Sta., Res. Note NC-299, 1983.

[14] Telfer E.S., Weight-diameter relationships for 22 woody plant species, Can. J. Bot. 47 (1969) 1851-1855.

[15] Ter-Mikaelian M.T., Korzukhin M.D., Biomass equations for sixty-five North American tree species, For. Ecol. Manage. 97 (1997) 1-24.
[16] Wagner R.G., Noland T.L., Mohammed G.H., Timing and duration of herbaceous vegetation control around four northern coniferous species, N. Z. J. For. Sci. 26(1/2) (1996) $39-52$.

[17] Whittaker R.H., Bormann F.H., Likens G.E., Siccama T.G., The Hubbard Brook ecosystem: Forest biomass and production, Ecol. Monogr. 44 (1974) 233-252.

[18] Williams R.A., McClenahen J.R., Biomass prediction equations for seedlings, sprouts, and saplings of ten central hardwood species, For. Sci. 30 (1984) 523-527.

[19] Young H.E., Ribe J.H., Wainwright K., Weight tables for tree and shrub species in Maine, Life Sci. Agric. Exp. Sta., Univ. Maine, Orono, Miscell. Rep. 230, 1980. 